\title{
Editorial
}

\section{2: nuevas y emergentes superficies \\ de inscripción para la investigación educativa}

La intensidad de 2021 fue una constante. Es posible encontrar múltiples huellas de ello en los distintos niveles y diversas dimensiones de la sociedad, de la realidad misma, de la pedagogía, de la educación y de la investigación educativa. El año 2020 estuvo signado por el temor y el desconocimiento del alcance de la pandemia, así como por la vigorosa respuesta del sector educativo, especialmente en el plano de los procesos y las prácticas. Tanto docentes como estudiantes de los distintos niveles educativos mostraron su creatividad, compromiso y resiliencia en el hecho de confrontar, en un contexto de gran incertidumbre, el despliegue de nuevas formas de enseñar y de aprender - caracterizadas por la tecnologíaen las experiencias didáctico-curriculares.

Asimismo, docentes y quienes se dedican principalmente a la investigación iniciaron sus tareas de reflexión, análisis y conceptualización del impacto de la pandemia en la educación. Todo ello abrió y modeló nuevas superficies de inscripción para el registro de experiencias complejas, dolorosas e incluso traumáticas en 2020 y buena parte de 2021.

A partir de la vacunación -y pese al temor de nuevas variantes del virus y la duración de la inmunidad proporcionada por los diferentes biológicos-, hemos constatado la urgencia de una vuelta a la presencialidad física en los diversos sectores sociales, entre ellos, desde luego, el de la educación. En este marco, 2022 se presenta como un año crucial para nutrir y consolidar esas superficies de inscripción pedagógica para narrar la ontología del presente que vivimos en la sociedad.

Tales superficies de inscripción interpelan a la investigación educativa y se traducen en espacios, líneas y temáticas para darle expresión a un futuro que de muchas maneras está y no está aquí, para construirlo día a día desde los distintos espacios de reflexión, investigación y de práctica que habitamos. Pareciera que, querámoslo o no, nuestra tarea a partir de este 2022 será construir pedacitos de presente-futuro.

Perfiles Educativos mantuvo su esfuerzo en 2020 y 2021 tanto por publicar avances de investigación, reflexiones y elaboraciones teóricas en las distintas áreas de la investigación educativa como por presentar suplementos o números especiales inextricablemente vinculados con los acontecimientos que signaron el presente. Pretendemos continuar este esfuerzo en 2022 que, por su momento y textura de emergencia, conlleva avances significativos y nodales en la investigación educativa. 
En el presente número contamos con trabajos de autores y autoras de Argentina, Chile, México y España. En la sección de Horizontes dos artículos abordan cuestiones centrales sobre el dilema de la inclusión en la educación superior y el neoliberalismo en una perspectiva histórica. En la sección de Claves los artículos con seguridad serán del interés de investigadoras e investigadores, así como de quienes se interesen en los textos presentados en la medida en que cubren un abanico importante de temáticas y líneas de investigación. Abordan cuestiones como las primeras publicaciones periódicas sobre la educación para la niñez mexicana en el siglo XIX, la maternidad y maternaje en mujeres docentes de Chiapas-México, la escuela en la cárcel, aprendizajes en red, docencia enfocada en el desarrollo de competencias y las desigualdades educativas en un ambiente urbano.

En la sección de Horizontes Judith Pérez Castro aborda, en su trabajo titulado "El dilema de la inclusión en la educación superior", la importancia de la inclusión en la educación superior y considera que los dilemas, en su carácter de construcciones sociohistóricas, abren espacios para la reflexión en los diversos aspectos de la educación. Otro artículo en esta sección aborda una temática que ha resurgido con fuerza a raíz de la pandemia: la relación de la educación con el neoliberalismo, de la autoría de Noelia Fernández González y Héctor Monarca en su artículo "Escuela, del liberalismo al neoliberalismo: tensiones entre el cercamiento y lo común".

De la gama de artículos en la sección Claves, el de María Esther Aguirre Lora nos presenta resultados inéditos de su investigación desde la historia cultural en el campo de la pedagogía referidos a la genealogía de las revistas dedicadas a la educación en México. De manera específica hace un close up en dos publicaciones mexicanas del siglo XIX: El Diario de los Niños (1839-1840) y Los niños pintados por ellos mismos (1843), las cuales estaban dirigidas a la formación, desde la infancia, de los nuevos ciudadanos que el proyecto de la modernidad requería. La escritura de Aguirre Lora se caracteriza por el tejido de contenidos originales, la rigurosidad académica y por dar cuenta de su entramado teórico y metodológico, todo ello anudado en su grata narrativa.

Los otros artículos de la sección de Claves, cuyas temáticas se enunciaron brevemente en párrafos anteriores, despertarán el interés de nuestros lectores y nuestras lectoras a quienes les enviamos nuestros mejores deseos de bienestar en todos los sentidos, en la tarea de la construcción común, social y pedagógica de este presente-futuro en el que vivimos. Con el agradecimiento de siempre por distinguirnos con su lectura.

Alicia de Alba 